\title{
Influence of Acoustic Waves on the Shelf Life Quality of Broccoli (Bsassica oleracea var. italic)
}

\author{
Dixie Pablo Asuncion", Jeffrey A. Lavarias\#, Andres M. Tuates Jr. , Carolyn Grace G. Somera \\ Ruel G. Peneyra\# \\ \# College of Engineering-Central Luzon State University, CLSU Compound, Science City of Muñoz, Nueva Ecija.3120. Philippines
}

*Philippine Center for Postharvest Development and Mechanizatio, CLSU Compound, Science City of Muñoz, Nueva Ecija.3120. Philippines E-mail:amtuates@yahoo.com

\begin{abstract}
Broccoli (Brassica oleracea var. italica) is a high value crop that requires the application of post-harvest techniques to extend its shelf life. Acoustic wave is one of the newest non thermal methods to extend shelf life of fresh produce during storage. The purpose of this study was to test the efficacy of prolonging the shelf life quality of broccoli through acoustic waves treatment. Experimental design includes 4 treatments with 3 replications each. The treatments consisted of varying hours of exposure to acoustic waves ( 0 hour, 4 hours, 6 hours, and 8 hours). Broccolis were treated with low-frequency acoustic waves at $1 \mathrm{kHz}, 100 \mathrm{~dB}$ produced by a sound transducer in a sound-proof chamber to prevent extraneous noise. After acoustic waves exposure, broccolis were stored in a refrigerator at $10{ }^{\circ} \mathrm{C}$ then monitored the surface color, florets firmness, stalk firmness, and the shelf life which are the quality indicator of broccoli. Results showed that treated broccoli has a significant difference compared to non-treated broccoli. Broccoli treated with acoustic waves exhibits gradual changes in its quality than of non-treated. The most suitable hours of exposure to acoustic waves to extend the shelf life quality of broccoli in terms of surface color and flesh firmness is achieved by treating the broccoli with $1 \mathrm{kHz}, 100 \mathrm{~dB}$ acoustic waves for 8 hours. The acoustic wave has a potential benefit of extending the shelf life of broccoli up to 22 days at $10{ }^{\circ} \mathrm{C}$ delaying the changes in marketable quality.
\end{abstract}

Keywords — broccoli; acoustic wave; shelf-life; quality; storage.

\section{INTRODUCTION}

The high-value vegetable crops, like broccoli, are a fantastic source of income for farmers, rural cooperatives and agri-business people because these vegetables command high prices in the retail market. Production of broccoli in the Philippines is going up by an average rate of $1.16 \%$ per year during the period. From 3,000 MT in 2012, it went up to 3,100 MT in 2014 [1].

Broccoli is one of the most expensive vegetables in the Philippines and is widely studied for its apparent ability to fight and even prevent many different cancers and other ills of the body [2]. It is accepted as a nutrient-abundant vegetable not merely because it contains rich vitamins, minerals, and dietary fiber content but also in as much as the presence of bio-active compounds, like phenolics, glucosinolates, and sulforaphane, etc., which have been confirmed by researchers to be beneficial to human health $[3,4]$.

Broccoli is an excellent source of vitamin $\mathrm{K}$, vitamin $\mathrm{C}$, chromium and folate. It is a very good source of dietary fiber, pantothenic acid, vitamin B6, vitamin E, manganese, phosphorus, choline, vitamin B1, vitamin A (in the form of carotenoids), potassium and copper. Broccoli is also a good source of vitamin B1, magnesium, omega-3 fatty acids, protein, zinc, calcium, iron, niacin and selenium [2].

Unfortunately, broccoli is a perishable crop with its shelf life usually ranges from 3-5 days when not in the fridge and lasts for 7-14 days if stored refrigerated [5]. It is important to store broccoli correctly in order to preserve its flavor and nutrients.

Food loss is significant in developing countries, like the Philippines. Food losses arise chiefly from the absence of proper food-chain infrastructure and the lack of knowledge about postharvest and storage technologies on the farm [6]. One of the causes of losses is inadequate storage practices and facilities. It is important to pay attention to prolonging the shelf life of the produced crops in order to minimize losses due to improper storage.

Application of acoustic waves in agriculture is an innovation arising nowadays, specifically, in the growth of plants. Acoustic wave has frequencies greater than $20 \mathrm{kHz}$ [7]. They also mentioned that sound waves significantly 
affect the number of sprouted okra and zucchini seeds. Acoustic wave treatment in the plant can be used as one of the growth promoter/regulator to increase the yield potential of crops [8]. Application of acoustic wave prior to storing of tomato can delay the ripening thereby prolonging its shelf life [9]. Acoustic wave is one of the newest non thermal methods to extend the shelf life of fresh produce during storage [10].

Experiments have been conducted in the open field and under greenhouse growing conditions with different levels of audible sound frequencies and sound pressure levels. Acoustic waves at $1 \mathrm{kHz}$ and $100 \mathrm{~dB}$ for 1 hour within 0.20 $\mathrm{m}$ could significantly promote the division and cell wall fluidity of callus cells and significantly enhance the activity of protective enzymes and endogenous hormones. Acoustic waves stimulation could increase the plant plasmamembrane $\mathrm{H}+$ - ATPase activity, the contents of soluble sugar, soluble protein, and amylase activity of callus. Moreover, acoustic waves could increase the content of RNA and the level of transcription. Stress induced genes could switch on under stimulation [7].

The general objective of this study was to investigate the influence of acoustic waves treatment in the shelf-life quality of broccoli.

\section{MATERIAL AND METHOD}

\section{A. Sound-proof Chamber}

A sound-proof chamber 30 " in length, 30" in width and 18 " in height was used in the study as shown in Figure 1. The chamber itself was assembled using 3/4" plywood. Improvised acoustical foam sound proof insulation was installed in the walls of the chamber. It was installed to ensure that there is no extraneous noise to prevent the transfer of vibrations and sounds from outside during the acoustic wave treatments. The produced $1 \mathrm{kHz}, 100 \mathrm{~dB}$ acoustic waves were measured by a sound level meter at a distance from the transducer where the crop was positioned.

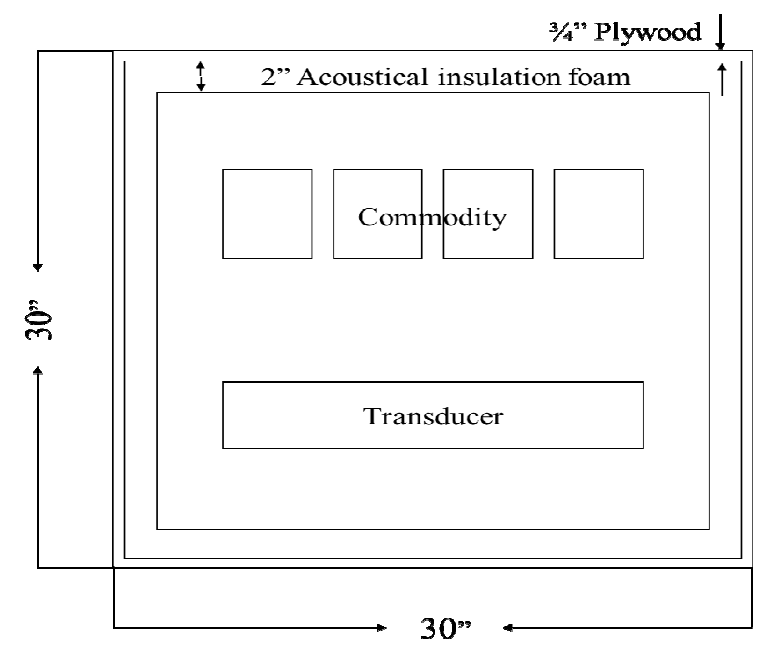

Fig. 1 Sound-proof chamber layout

\section{B. Preparation of the Set-up}

In a sound-proof chamber, the location of the transducer speaker was in front of the broccoli during exposure to promote equal distribution of acoustic waves. After exposing the broccoli to $1 \mathrm{kHz} 100 \mathrm{~dB}$ acoustic wave, broccolis were stored in a refrigerator with a temperature of $10 \mathrm{oC}$. Freshly harvested broccolis were collected straight from the farm in Buguias, Benguet. Samples were free from physical injuries and other external factors that may lead to early deterioration.

\section{Storage of Broccoli}

During storing of the broccoli with different treatment, the arrangement in the refrigerator at $10 \mathrm{oC}$ was based on the statistical layout with respect to treatment and replication. The daily temperatures in the refrigerator were recorded using temperature and humidity meter.

\section{Acoustic Waves}

Acoustic waves at $1 \mathrm{kHz}, 100 \mathrm{~dB}$ were produced using a tone generator software and sound transducer. In this study, JHW-V621 wireless speaker as shown in Figure 9 was used to produce $1 \mathrm{kHz} 100 \mathrm{~dB}$ acoustic waves. The sound level meter was used to measure the acoustic waves produces to verify the $1 \mathrm{khz}, 100 \mathrm{~dB}$ acoustic waves.

\section{E. Flesh Firmness}

The compactness of broccoli florets and the crispness of broccoli stalk were determined by using Shimadzu Table Top Type Tester EZTest Series (Figure 2). Data were gathered at various time points after treating the broccoli with $1 \mathrm{kHz}, 100 \mathrm{~dB}$ acoustic waves prior to storage.

The flesh firmness of the broccoli was measured using the penetrometer. Initial flesh firmness was recorded. The flesh firmness of the broccoli during the experiment was measured at various time points. This data was used for the comparison during the analysis of the results.

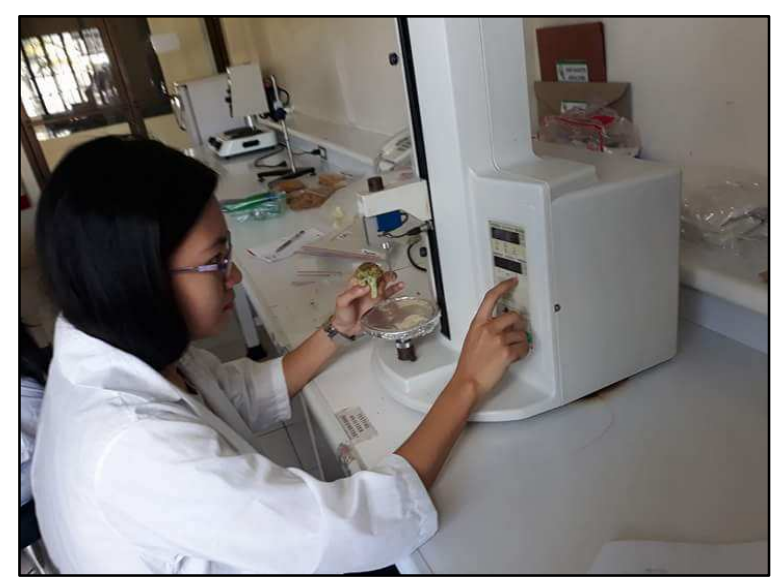

Fig. 2 Shimadzu Table Top Type Tester-EZTest Series

\section{F. Surface Color}

The surface color of the broccoli was measured using the Chromameter (CR-400/410) Konica Minolta (Figure 3). The initial surface color was recorded. The surface color of the broccoli during the experiment was measured at various time points. This data was used for the comparison during the analysis of the results.

\section{G. Shelf life}

The shelf life of broccolis was determined by counting the number of days from the day freshly harvested broccoli were stored until they reached the unmarketable quality condition. It was determined whether acoustic waves will extend the 
shelf-life quality of the broccoli. Good quality broccoli should have dark or bright green closed florets, and the head should be compact, firm to hand pressure as shoen in Table 1.

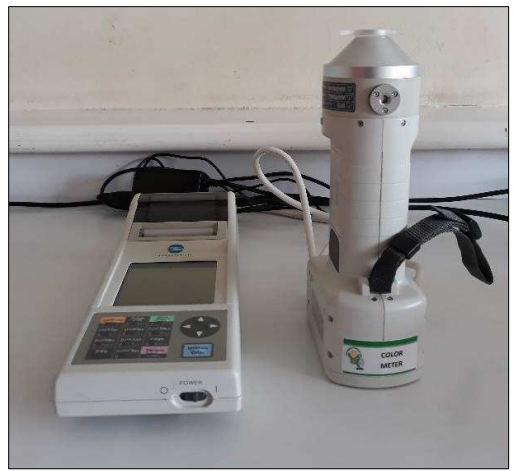

Fig. 3 Chromameter (CR-400/410) Konica Minolta

TABLE I

DESCRIPTION OF NUMERICAL RATINGS FOR BROCCOLI QUALITY

\begin{tabular}{|c|c|c|c|c|c|}
\hline \multirow{2}{*}{ Trait } & \multicolumn{5}{|c|}{ Desciption of rating } \\
\cline { 2 - 6 } & 1 & 2 & 3 & 4 & 5 \\
\hline color & $\begin{array}{c}\text { dark } \\
\text { green }\end{array}$ & green & $\begin{array}{c}\text { light } \\
\text { green }\end{array}$ & $\begin{array}{c}\text { slightly } \\
\text { yellow }\end{array}$ & $\begin{array}{c}\text { severe } \\
\text { yellow }\end{array}$ \\
\hline $\begin{array}{c}\text { Compactness } \\
\text { of head }\end{array}$ & tight & $\begin{array}{c}\text { trace } \\
\text { loose }\end{array}$ & $\begin{array}{c}\text { slightly } \\
\text { loose }\end{array}$ & $\begin{array}{c}\text { Moderately } \\
\text { loose }\end{array}$ & $\begin{array}{c}\text { very } \\
\text { loose } \\
\text { and limp }\end{array}$ \\
\hline $\begin{array}{c}\text { Market } \\
\text { quality }\end{array}$ & $\begin{array}{c}\text { very } \\
\text { good }\end{array}$ & good & $\begin{array}{c}\text { fair but } \\
\text { saleable }\end{array}$ & $\begin{array}{c}\text { poor but } \\
\text { saleable }\end{array}$ & $\begin{array}{c}\text { Severe, } \\
\text { unsaleable, } \\
\text { unusable }\end{array}$ \\
\hline
\end{tabular}

Adapted from Tomkins, et al., [13]

\section{H. Statistical Analysis and Experimental Design}

In this study, broccoli was exposed to $1 \mathrm{kHz}$ at $100 \mathrm{~dB}$ acoustic waves prior to storage. There were four treatments, Treatment 1 - unexposed broccoli (control), Treatment 2 broccoli exposed to acoustic waves for 4 hours, Treatment 3 - broccoli exposed to acoustic waves for 6 hours, and Treatment 4 - broccoli exposed to acoustic waves for 8 hours. After the exposure, broccoli was stored in a refrigerator at $10 \mathrm{oC}$. Data concerning the surface color and flesh firmness of the crop were collected at various time points until the crop is unmarketable.

Completely Randomized Design (CRD) was used to analyze the data collected. Analysis of Variance (ANOVA) was used to determine the level of significance among treatments. Comparison among means was done using Duncan's Multiple Range Test (DMRT). A 5\% level of significance was used.

\section{RESULT AND DISCUSSION}

\section{A. Surface Color}

Table 2 shows the change in color $(\Delta \mathrm{E})$ occurred in the broccoli per treatment at 14 days storage period. The highest change in color was exhibited by the broccoli samples without exposure to acoustic waves. The decrease in green color $\left(-\mathrm{a}^{*}\right)$ and an increase in yellow color $\left(\mathrm{b}^{*}\right)$ is higher at various time of sampling in broccoli samples without exposure compared to samples treated with acoustic waves. It was observed that acoustic waves influenced the slowed down of color change and the discoloration as compared to the non-treated broccoli.
TABLE II

Change In Color $(\Delta \mathrm{E})$ OF BRocColi Florets AT DAY 14

\begin{tabular}{|c|c|c|c|c|}
\hline \multirow{2}{*}{ Treatment } & \multicolumn{3}{|c|}{ Replicate } & \multirow{2}{*}{ Mean } \\
\cline { 2 - 4 } & 1 & 2 & 3 & \\
\hline T1 (0 hour) & 19.65 & 18.19 & 22.07 & $19.97^{\mathrm{a}}$ \\
\hline T2 (4 hours) & 20.22 & 18.54 & 7.53 & $15.43^{\mathrm{ab}}$ \\
\hline T3 (6 hours) & 8.96 & 9.53 & 12.92 & $10.47^{\mathrm{b}}$ \\
\hline T4 (8 hours) & 8.32 & 12.60 & 7.51 & $9.48^{\mathrm{b}}$ \\
\hline
\end{tabular}

Means not sharing letter in common differ significantly by Duncan's Multiple Range Test at $5 \%$ level of significance

Analysis of variance for the surface color of broccoli revealed that acoustic waves had a significant effect on the surface color of broccoli.

\section{B. Color Development}

Color development and chart show the color change of broccoli in every treatment with respect to the number of days of storage in the refrigerator at $10{ }^{\circ} \mathrm{C}$. It is also indicating the change in the marketability of the broccoli since the surface color is the most important external characteristic for visual assessing of marketability of broccoli. Color development of every treatment was presented in Figure 4, 5, 6, 7 and 8.

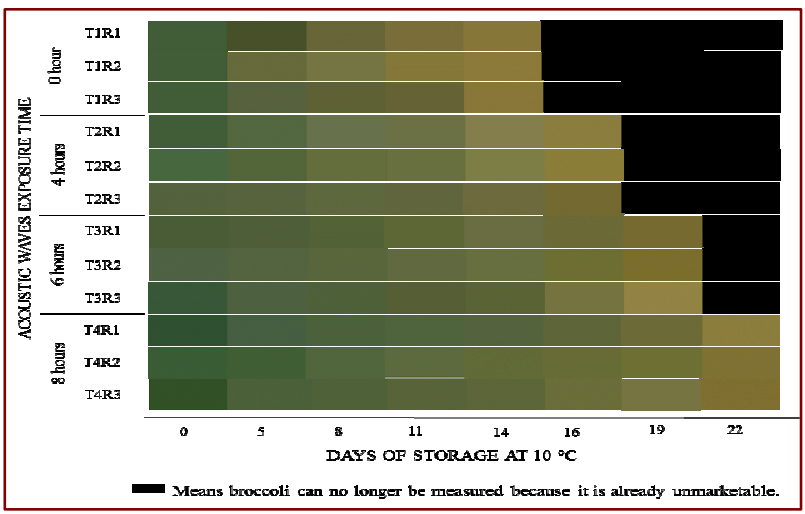

Fig. 4 Color development chart of broccoli samples

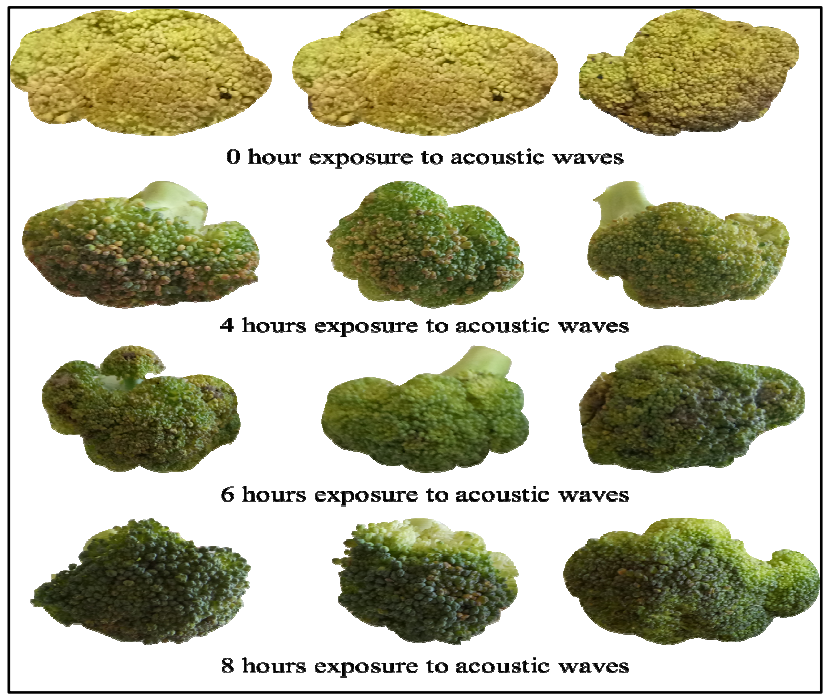

Fig. 5 Broccoli samples at 14 days 

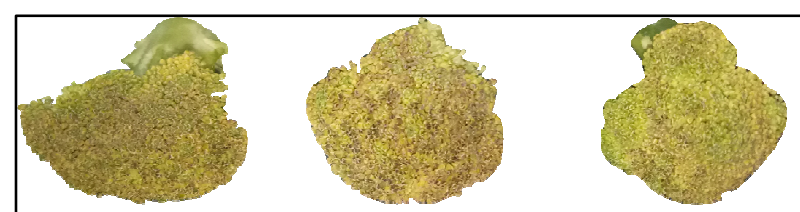

4 hours exposure to acoustic waves
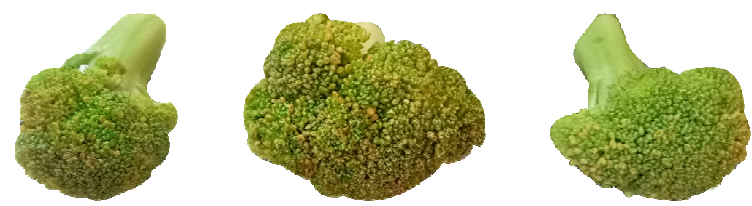

6 hours exposure to acoustic waves
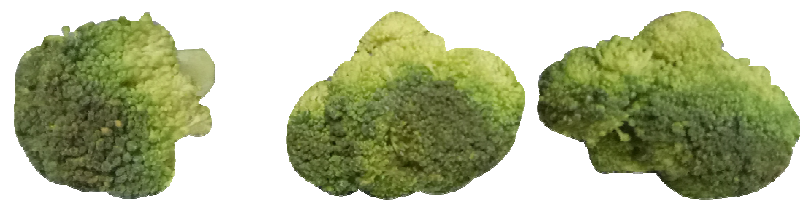

8 hours exposure to acoustic waves

Fig. 6 Broccoli samples at 16 days

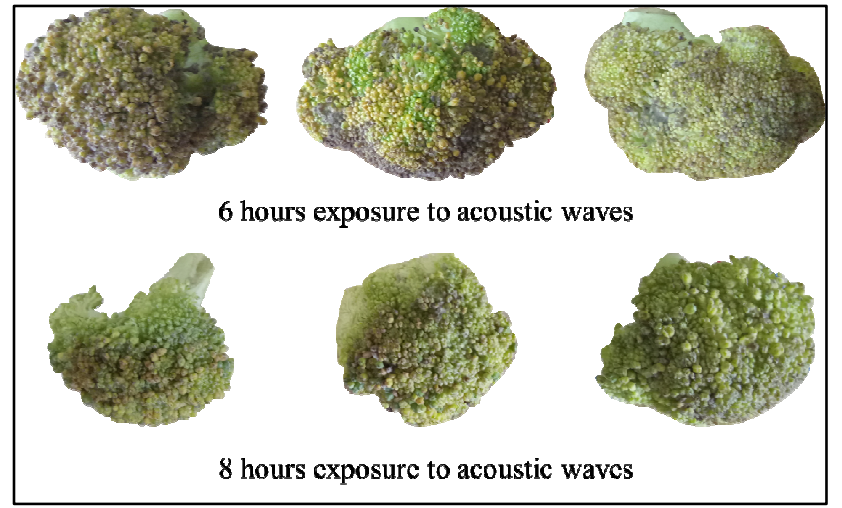

Fig. 7 Broccoli samples at 19 days
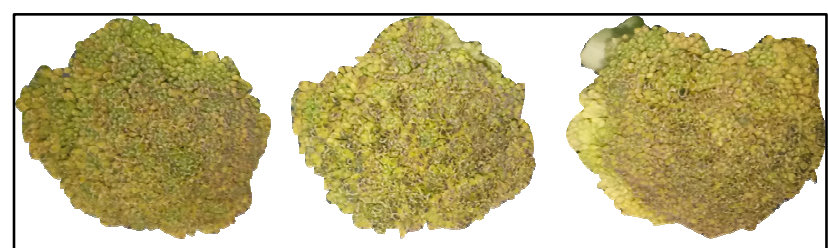

8 hours exposure to acoustic waves

Fig. 8 Broccoli samples at 22 days

It was observed that broccoli samples exposed to acoustic waves for eight hours prior to storage took a longer time to reach the unmarketable color condition. It was observed that exposing broccoli samples to acoustic waves for 8 hours resulted to have the longest time in color transition from green to yellow.

\section{Firmness}

Firmness, or the degree of crispness or compactness, is often measured using objective instruments. The florets are the most perishable part of the broccoli head [11]. Table 3 shows the change in firmness or compactness of broccoli florets after 14 days of storage. Negative change values indicate that the broccoli florets samples attained higher value with respect to storage days. Subsequently, the higher the value of firmness of broccoli florets, the loser become. On the other hand, Figure 9 shows the florets firmness with respect to storage days at a refrigerator with $10{ }^{\circ} \mathrm{C}$.

Based on the graph, 0-hour exposure exhibited a sudden change in florets firmness as compared to those broccoli samples exposed to acoustic waves reaching the unmarketable condition at around 14 days. Four hours, six hours and eight hours of exposure to acoustic waves gradually changed their firmness. All things considered, eight hours of exposure shows the least change in florets firmness.

Acoustic waves treated broccoli showed comparatively better retention of compactness of broccoli florets than nontreated broccoli over the storage period, although the firmness of the samples decreased with increase in storage period as compared to day 1 .

TABLE III

Change In The Firmness OF BROCCOLI Florets At DAy 14, $\Delta \mathrm{F}(-)$

\begin{tabular}{|c|c|c|c|c|}
\hline \multirow{2}{*}{ Treatment } & \multicolumn{3}{|c|}{ Replicate } & \multirow{2}{*}{ Mean } \\
\cline { 2 - 4 } & 1 & 2 & 3 & \\
\hline T1 (0 hour) & 2.48 & 1.74 & 1.60 & $1.94^{\mathrm{b}}$ \\
\hline T2 (4 hours) & 1.04 & 0.86 & 1.23 & $1.04^{\mathrm{a}}$ \\
\hline T3 (6 hours) & 0.84 & 0.23 & 0.34 & $0.47^{\mathrm{a}}$ \\
\hline T4 (8 hours) & 0.44 & 0.53 & 1.35 & $0.77^{\mathrm{a}}$ \\
\hline
\end{tabular}

Means not sharing letter in common differ significantly by Duncan's Multiple Range Test at $5 \%$ level of significance

Analysis of variance shows that the acoustic waves treated broccoli had a highly significant effect on the compactness of broccoli florets. Good quality broccoli should have dark or bright green closed florets and should be compact [9].

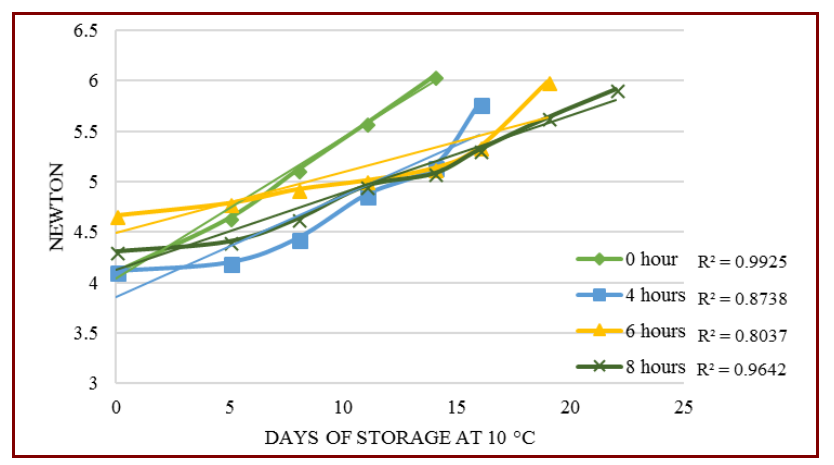

Fig. 9 Florets firmness of broccoli with respect to storage days

\section{Shelf Life}

Shelf life is the length of time that a commodity may be stored without becoming unfit for use, consumption, or sale [12]. The shelf life of the broccoli used in this study was determined by counting the number of days from the day it was stored in the refrigerator until the broccoli reached the stage where it is unmarketable [13]. Figure 10 shows the broccoli scale used as the basis of ending the shelf life of broccoli. when broccoli reached the scale of 5 , it is considered unmarketable and unusable. The shelf life of broccoli as influenced by the acoustic waves is shown in Table 4. The broccoli samples exposed in acoustic waves for eight hours had the longest shelf life among treatments having 22 days followed by broccoli samples exposed for six hours with 19 days shelf life and four hours of exposure to 
acoustic waves had 16 days shelf life. The non-treated broccoli had the lowest shelf life having 14 days. The shelf life of broccoli may vary up to $10-15$ days stored in $10^{\circ} \mathrm{C}$ depending on where it is cultivated [14].

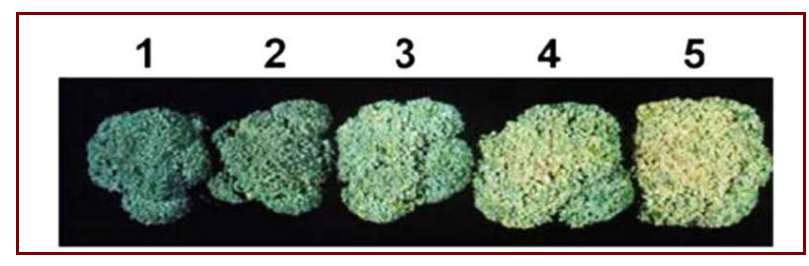

Fig. 10 Broccoli yellowing scale

TABLE IV

SHELF Life Of BRoccoli As AFFeCted By ACOUSTIC WaVes With DIFFERENT EXPOSURE TIME, DAYS

\begin{tabular}{|c|c|c|c|c|}
\hline \multirow{2}{*}{ Treatment } & \multicolumn{3}{|c|}{ Replicate } & \multirow{2}{*}{ Mean } \\
\cline { 2 - 4 } & 1 & 2 & 3 & \\
\hline T1 (0 hour) & 14 & 14 & 14 & $14^{\mathrm{d}}$ \\
\hline T2 (4 hours) & 16 & 16 & 16 & $16^{\mathrm{c}}$ \\
\hline T3 (6 hours) & 19 & 19 & 19 & $19^{\mathrm{b}}$ \\
\hline T4 (8 hours) & 22 & 22 & 22 & $22^{\mathrm{a}}$ \\
\hline
\end{tabular}

Means not sharing letter in common differ significantly by Duncan's Multiple Range Test ranked at probability level .05

Analysis of variance revealed that acoustic waves had a highly significant effect on the shelf life of broccoli. Broccoli exposed in acoustic waves for eight hours had the longest shelf life attaining 22 days while the non-treated broccoli attained 14 days shelf life. This result supports the growing interest in the further exploring in the potential of acoustic waves in extending the shelf life of a perishable crop.

\section{E. Hours of Exposure}

The eight hours of exposure of broccoli to acoustic waves had achieved the longest shelf life which lasted for 22 days maintaining its marketable quality. The least number of days observed was on 16 days when broccoli samples exposed to 4 hours of acoustic waves. The same trend was observed on prolonging the shelf life of a tomato [9].

\section{F. Quality of Broccoli Treated with Acoustic Waves and Non-treated}

Comparison in the shelf-life quality of broccoli treated with acoustic waves and non-treated broccoli was done based on the results of the data measurement in surface color, florets and stalk firmness and shelf life of broccoli. Normally, the shelf life of broccoli lasts 10-15 days under refrigerated storage of $10^{\circ} \mathrm{C}$ [14]. The shelf life of broccoli treated with acoustic waves differs significantly compared to the nontreated broccoli in terms of surface color and stalk firmness while regarding the florets compactness the application of acoustic waves had a highly significant effect. Acoustic waves treatments were able to extend the shelf-life quality of broccoli samples for a few days compared to zero application of acoustic waves.

\section{CONCLUSIONS}

Based on the findings in this study it can be concluded that acoustic waves can be an effective post-harvest treatment in prolonging the shelf life and marketable quality of broccoli compared to the untreated broccoli. Acoustic waves treatment had a positive effect in delaying color and firmness changes of the broccoli. The shelf life and marketable quality of broccoli could be prolonged up to 22 days by exposing it to $1 \mathrm{kHz}, 100 \mathrm{~dB}$ acoustic waves at 8 hours prior to storage at $10^{\circ} \mathrm{C}$. Application of acoustic waves can be a potential supplement to refrigerated storage to further extends the shelf life quality of broccoli.

\section{ACKNOWLEDGMENT}

We would like to thank Philippine Center for Postharvest Development and Mechanization for allowing to use their laboratory, equipment and instruments, and experimental area.

\section{REFERENCES}

[1] Philippine Statistics Authority. 2015. Supply Utilization Accounts, Philippines, 2012 - 2014

[2] Mercola, J. 2002. Superfoods. Supercharge Your Health and Nutrition Naturally.

[3] Herr, I., and M.W. Büchler. 2010. Dietary Constituents of Broccoli and Other Cruciferous Vegetables: Implications for Prevention and Therapy of Cancer. Cancer Treatment Reviews, 36(5), 377- 383.

[4] Mahn, A., and A. Reyes. 2012. An Overview of Health-Promoting Compounds of Broccoli (Brassica oleracea var. italica) and The Effect of Processing. Food Science and Technology International, 18(6), 503-514

[5] EatByDate. 2012. Shelf life of Broccoli.

[6] Godfray, H.C.J., J.R. Beddington, I.R. Crute, L. Haddad, D. Lawrence, J.F. Muir, J. Pretty, S. Robinson, S.M. Thomas, C. Toulmin. 2010. Food security: the challenge of feeding 9 billion people. science, 327(5967), 812-818.

[7] Hassanien R. H. Tian-Zhen, L., Yu-Feng and Bao-Ming. 2014 Advances in Effects of Sound Waves on Plants. Journal of Integrative Agriculture. Volume 13, Issue 2. Pages 335-348.

[8] Mohanta, T.P. 2007. Sound Wave in Plant Growth Regulation: A Review of Potential Biotechnological Applications. The Journal of Animal Plant Science. 28(1).

[9] Kim, J.Y., J.S. Lee, T.R. Kwon, S.I. Lee, J.A. Kim, G.M. Lee, S.C. Park, and M.J. Jeong. 2015. Sound Waves Delay Tomato Fruit Ripening by Negatively Regulating Ethylene Biosynthesis and Signaling Genes.

[10] Bal, E. 2013. Effects of Exogenous Polyamine and Ultrasound Treatment to Improve Peach Storability. CHILEAN Journal of Agricultural Research. Volume 73 (4).

[11] Cantwell, M. and S. Trevor. 1997. Broccoli: Recommendations for Maintaining Post-Harvest Quality.

[12] Munawar, K. 2013. Difference Between Expiry Date and Shelf Life.

[13] Tomkins, B., J. Sutherland, and B. Davis. 1989. Sea Freight of Fresh Broccoli. Marketing Report Series No. 19. Department of Agriculture and Rural Affairs, Victoria, Australia.

[14] Watada, A.E., H. Izumi, and W. Douglas. 1996. Optimum O2 or CO2 Atmosphere for Storing Broccoli Florets at Various Temperature.

[15] Abdalla, N.A., H.R. El-Ramady, E.D. Szabolcsy, S.H. Taha, and M. Fári. 2015. Postharvest Management of Fruits and Vegetables Storage.

[16] DBA Instrumart. 2018. About Sound Level Meters. Calibration of a Sound Level Meter.

[17] Kochhar, V. and S. Kumar. 2015. Effect of Different Pre-Cooling Methods on the Quality and Shelf Life of Broccoli.

[18] Lagnika C, Zhang, M, Atindana J.N, And Bashari, M. 2014. Effects of Ultrasound and Chemical Treatments on White Mushroom (Agaricus Bisporus) Prior to Modified Atmosphere Packaging in Extending Shelf-Life.

[19] Nave, R. 2017. Estimating Sound Levels with the Inverse Square Law.

[20] Owis, A. I. 2015. Broccoli; The Green Beauty: A Review. Journal of Pharmaceutical Sciences \& Research. Volume 7 (9). Pages 696-703. 